\title{
Factors Affecting Readiness to Change among Literate Obese Patients in Primary Care
}

\author{
Oyebanji Ayodele Emmanuel ${ }^{1}$, Dankyau Musa ${ }^{2, *}$ \\ ${ }^{1}$ Department of Family Medicine, Brigade Medical Centre, Yola, Nigeria \\ ${ }^{2}$ Department of Family Medicine, Bingham University Teaching Hospital, Jos, Nigeria
}

Email address:

drayodeleoyebanji@yahoo.com (O. A. Emmanuel),dankyau@gmail.com (D. Musa)

\section{To cite this article:}

Oyebanji Ayodele Emmanuel, Dankyau Musa. Factors Affecting Readiness to Change among Literate Obese Patients in Primary Care. American Journal of Applied Psychology. Vol. 4, No. 4, 2015, pp. 105-110. doi: 10.11648/j.ajap.20150404.14

\begin{abstract}
Background: Obesity is a chronic disease which contributes to morbidity and mortality from non-communicable diseases. Urbanization, western lifestyles and demographic transition contribute to this problem in Nigeria. Primary care physicians should be active in early detection, and motivating obese people for life style change. Motivation is an important first step towards any action or behaviour change and clinicians can assess and enhance motivation to change before extensive damage is done to health, relationships, reputation, or self-image. Aims: To determine pattern and predictive factors for readiness to change among literate obese patients in primary care. Methods and Materials: A cross-sectional study was conducted between July and October 2012, among literate obese patients in the outpatient department of an urban hospital. Obese patients were identified by clinical examination, and readiness to change was measured with the University of Rhode Island Change Assessment (URICA) score. Results: Prevalence of obesity was $17.43 \%$. Most of the subjects were married $(83.8 \%)$, female $(76.5 \%)$ had tertiary education $(64.7 \%)$ and from professional cadre $(54.4 \%)$. Mean age was $43.5 \pm 9.2$. Majority (69.1\%) felt that they were motivated (self- perception) to lose weight, but most (58\%) were not confident that they could lose weight (self-efficacy). Based on the URICA score, most (73.5\%)of the literate obese patients were contemplators. There were no significant predictors of the stage of change. Conclusion: Obesity is common among literate patients in the outpatient setting. The mean URICA score was $8.68 \pm 1.68$, and most were in contemplation stage.
\end{abstract}

Keywords: Obesity, Weight Loss, Lifestyle, Stages of Change, URICA

\section{Introduction}

Obesity is a chronic multifactorial disease that involves an imbalance of energy intake and caloric expenditure, and is influenced by socioeconomic status, cultural, psychological, environmental, metabolic and genetic factors as well as lifestyle. ${ }^{1}$ Although several classifications and definitions for degrees of obesity are accepted, the most widely accepted classifications are those from the World Health Organization (WHO), based on Body Mass Index (BMI). ${ }^{2}$ BMI (Quetelet index) is calculated by dividing the weight (in $\mathrm{Kg}$ ) by the square of the height (in metres). ${ }^{2}$ BMI has the advantage of not being age, gender or ethnicity specific. ${ }^{3}$ Other measurements of fat distribution include the waist-hip ratio and body fat percentage. ${ }^{4}$ BMI is an accurate reflection of body fat percentage in the majority of the adult population., Based on BMI, WHO classifies obesity into the following categories;
1. Underweight $\mathrm{BMI}=<18.5 \mathrm{~kg} / \mathrm{m}^{2}$

2. Ideal or normal BMI $=18.5$ to $24.9 \mathrm{~kg} / \mathrm{m}^{2}$

3. Overweight $\mathrm{BMI}=25.0$ to $29.9 \mathrm{~kg} / \mathrm{m}^{2}$

4. Obese BMI $\geq 30.0 \mathrm{~kg} / \mathrm{m}^{2}$

i. Obesity class $1=30-34.9 \mathrm{~kg} / \mathrm{m}^{2}$

ii. Obesity class $2=35-39.9 \mathrm{~kg} / \mathrm{m}^{2}$

iii. Extreme obesity, BMI $\geq 40.0 \mathrm{~kg} / \mathrm{m}^{2}$ (known as morbid obesity)

Some authors use a different classification to recognize particularly severe obesity as follows: ${ }^{2-5}$

1. Severe obesity - BMI greater than $40 \mathrm{~kg} / \mathrm{m}^{2}$

2. Morbid obesity - BMI of $40-50 \mathrm{~kg} / \mathrm{m}^{2}$

3. Super obesity - BMI greater than $50 \mathrm{~kg} / \mathrm{m}^{2}$

Waist Circumference (WC) greater than $88 \mathrm{~cm}$ in women and WC greater than $102 \mathrm{~cm}$ in men are also used as measures of central obesity, while that measured by BMI is referred to as generalized obesity. ${ }^{5}$ It is less accurate in body builders and pregnant women. ${ }^{5,6}$ Based on BMI, the prevalence of obesity in the United States was found to be $33.8 \%$ in a 
survey conducted from 2007 to $2008,{ }^{7}$ while in the United Kingdom, the prevalence is $23 \%$ among men and $24 \%$ among women. ${ }^{8}$ In Ghana obesity is found in $13.6 \%$ of adults, ${ }^{9}$ while in Republic of Benin, it is found in $18 \%$ of adults. ${ }^{10}$ Abubakari et al reported a prevalence of $10 \%$ in the West African sub-region with the odds of being obese being 3.2 among urban women compared to men. ${ }^{11}$ Nutritional transition as a result of urbanization, adoption of western lifestyles and demographic transition are implicated for the rising prevalence. ${ }^{12}$ Obesity is associated with increased prevalence of non-communicable diseases such as hypertension, insulin resistant type 2 diabetes mellitus, hypercholesterolemia and coronary heart disease. ${ }^{1}$ When these occur in conjunction with obesity outcomes are worsened, hence the need for prevention, early detection and motivating people for life style change. ${ }^{1}$ Obesity is a serious and growing health problem, but it is not receiving the attention it deserves from primary care practitioners. ${ }^{13}$

Motivation pervades all activities of life, operating in multiple contexts. ${ }^{14}$ It is the driving force by which humans achieve their goals, and could be intrinsic or extrinsic. ${ }^{15,16}$ Motivation for change involves having the belief that changing one's behaviour can influence an outcome. ${ }^{15,16}$ Consequently, motivation can be modified or enhanced at many points in the change process. ${ }^{17-20}$ Clients may not have to experience terrible, irreparable consequences of their behaviours to become aware of the need for change. ${ }^{17-20}$ Sayings such as "You can lead a horse to water, but you can't make it drink" reflect the fact that people generally will not perform desired behaviours unless or until they are motivated to do so. ${ }^{18}$ Client motivation for change is not a single attribute, but varies in intensity, ${ }^{16}$ and is critical for behavioural weight loss programmes. ${ }^{16-20}$

The role of the motivational type cognitive process in changing behaviour became a question of great importance in the field of psychology in the $1970 \mathrm{~s}^{18-20}$ The development of the motivational interview in the $80 \mathrm{~s}$ also emphasised the importance of motivation. ${ }^{18-20}$

Research investigating sources of motivation for change typically have compared intrinsic sources of motivation (e.g. feeling a sense of accomplishment, spiritual experiences and health concerns) with extrinsic sources (e.g., financial incentives, social and situational influences). ${ }^{16-20}$

\section{URICA Tool for Measuring Motivation}

Motivation is measured in highly variable and interchangeable ways. ${ }^{21} \mathrm{McC}$ Connaughy, and colleagues, created a stages-of-change measure, which was aptly named the "Stages of Change Scale"; it was later renamed the University of Rhode Island Change Assessment (URICA). ${ }^{22}$ It is the most widely studied generic measure of readiness for change. ${ }^{16,22,23}$ One reason is due to its focus on a general "problem," whereas other measures specify the target behaviour (e.g. smoking) and typically provide a timeline or frequency of usage. ${ }^{16,22,23}$ Consequently, URICA can be used to assess change readiness regarding a range of problemsincluding, obesity, and diet and weight management. ${ }^{23,24}$ The URICA has various versions (12 item, 24 item and 32 item), with higher scores indicating a greater Readiness To Change score (RTC). ${ }^{22}$

The URICA 32-item self-report measure includes subscales measuring the Prochaska's trans-theoretical model of stages of change: PC, C, A, and M (Pre-contemplation, contemplation, action and maintenance). Responses are given on a 5-point Likert scale ranging from 1 (strong disagreement) to 5 (strong agreement). ${ }^{16}$ The subscales can be combined arithmetically $(\mathrm{C}+\mathrm{A}+\mathrm{M}-\mathrm{PC})$ to yield a second-order continuous RTC score that can be used to assess RTC at entrance to treatment. ${ }^{16}$ The 32 item version provides a continuous measure of differences in attitude for individuals in each of the four distinct stages of change, thus generating a readiness profile rather than discrete placement at any particular stage. 22

Some researchers have argued that the scores are not adequately measuring the same underlying stages of change process. $^{24}$ Despite these criticisms, multidimensional approaches like the URICA, continue to be popular among clinicians and researchers. In a study including many African Americans, the construct validity of the URICA score was reported to be 0.8 , for pre-contemplation, 0.83 for contemplation, 0.67 for action, and 0.85 for maintenance. ${ }^{25}$

This study was aimed at determining the pattern and predictorsof readiness for life style change among literate obese patients in a primary care setting in urban Nigeria. This was the first stage of a study which aimed to examine the effect of counselling on motivation for life-style change in literate obese patients.

\section{Methods}

This study was carried out between July and October 2012 . A total of 68 patients were recruited for the study. A structured questionnaire was administered to elicit sociodemographic information. Anthropometric data were obtained by physical examination. Weight was measured to the nearest $0.5 \mathrm{~kg}$ using a weighing scale with the participants wearing light clothing and removing footwear. Height was measured to the nearest $0.5 \mathrm{~cm}$ using a stadiometer. The BMI was calculated as weight in kilograms divided by the square of the height in metres. The WC was measured at the level of the iliac crest, using a flexible tape passing along the umbilical level of the unclothed abdomen. Based on the WHO criteria for obesity, participants who's BMI were up to $30 \mathrm{~kg} / \mathrm{m}^{2}$ and above were regarded as obese.

Motivation was measured using the URICA questionnaire. The total URICA score (RTC score) was calculated for each patient. This was used to classify patients into TTM stage of change group as follows:

1. Readiness to change score of $<8$ : Pre-contemplation.

2. Readiness to change score of 8-12: Contemplation.

3 . Readiness to change score of $>12$ : Preparation to action. Self-efficacy was measured using a five point Likert scale.

Ethics: Approval for the study was obtained from the 
Health Research Ethics committee of the Bingham University Teaching Hospital Jos. Informed consent was obtained from each participant.

Statistics: Statistical Package for Social Sciences (SPSS) version 20 software was used for data analysis. Mean values and standard deviations were calculated for continuous variables, and the means compared using independent sample t-test. Pearson chi square was used to test for bivariate relationships while multinomial regression was used to test for multivariate relationships. Values of $\mathrm{P}<0.05$ were considered statistically significant.

\section{Results}

The prevalence rate of obesity was $17.43 \%$ among patients Most of the subjects were married (83.8\%), female $(76.5 \%)$ had tertiary education $(64.7 \%)$ and were of the professional cadre $(54.4 \%)$ while $41.1 \%$ were self-employed. Majority $(38.2 \%)$ of the participants were in the $41-50 \mathrm{yr}$ age group (mean age was 43.5 \pm 9.2 ) and earned more than forty thousand naira. Most of the participants (69.1\%) felt that they were motivated (self- perception) to lose weight but majority of them (58\%) were not confident that they could lose weight (self-efficacy). Most (67.7\%) had at least one co-morbidity. Other details are in Table 1.

Table 1. Socio-demographic characteristics of the study population.

\begin{tabular}{|c|c|c|}
\hline Variable & Number (N) & Percentage (\%) \\
\hline \multicolumn{3}{|l|}{ Age group (years) } \\
\hline - $21-30$ & 3 & 4.4 \\
\hline - $\quad 31-40$ & 24 & 35.3 \\
\hline - $41-50$ & 26 & 38.2 \\
\hline - $51-60$ & 13 & 19.1 \\
\hline - $>60$ & 2 & 2.9 \\
\hline \multicolumn{3}{|l|}{ Sex } \\
\hline - Female & 52 & 76.5 \\
\hline - Male & 16 & 23.5 \\
\hline \multicolumn{3}{|l|}{ Marital status } \\
\hline - Divorced & 2 & 2.94 \\
\hline - Married & 57 & 83.82 \\
\hline - Single & 7 & 10.30 \\
\hline - Widowed & 2 & 2.94 \\
\hline \multicolumn{3}{|l|}{ Educational status } \\
\hline - Primary & 13 & 19.1 \\
\hline - Secondary & 11 & 16.2 \\
\hline - Tertiary & 44 & 64.7 \\
\hline \multicolumn{3}{|l|}{ Occupational group } \\
\hline - Manual worker & 2 & 2.9 \\
\hline - Self-employed & 28 & 41.2 \\
\hline - Professional & 37 & 54.4 \\
\hline - Unemployed & 1 & 1.5 \\
\hline \multicolumn{3}{|c|}{ Monthly income group (Naira) } \\
\hline - $0-10,000$ & 10 & 14.7 \\
\hline - $10,001-20,000$ & 7 & 10.3 \\
\hline - $20,001-30,000$ & 13 & 19.1 \\
\hline - $30,001-40,000$ & 3 & 4.4 \\
\hline
\end{tabular}

\begin{tabular}{lll}
\hline Variable & Number (N) & Percentage (\%) \\
\hline - >40,000 & 35 & 51.5 \\
Ethnic group & & \\
- Igbo & 13 & 19.1 \\
- Berom & 7 & 10.3 \\
- Igala & 4 & 5.9 \\
- Yoruba & 4 & 5.9 \\
- Others (25) & 40 & 58.8 \\
Self-perception of motivation to change & \\
- Yes & 47 & 69.1 \\
- No & 21 & 30.9 \\
Self-assessment of efficacy & & \\
- Yes & 28 & 41.2 \\
- No & 40 & 58.8 \\
Illness presentation & & \\
Nil & 22 & 32.4 \\
- Hypertension & 14 & 20.6 \\
- Arthritis & 6 & 8.8 \\
- Diabetes mellitus & 3 & 4.4 \\
- Others (18) & 23 & 33.8 \\
\hline
\end{tabular}

Anthropometric measurements of the study participants.

The mean weight was $100.2 \pm 12.69 \mathrm{Kg}$, mean height was $1.63 \pm 0.09 \mathrm{~m}$, and mean BMI was $37.6 \pm 4.3\left(\mathrm{Kg} / \mathrm{m}^{2}\right)$. The males had a mean abdominal circumference of $119.3 \pm 17.3 \mathrm{~cm}$ while that of the females was $111.2 \pm 8.9 \mathrm{~cm}$.

DISTRIBUTION OF BMI: Most of the participants $(45.6 \%)$ were in obese class II. Other details are in Table 2.

Table 2. Distribution of bmi in the study

\begin{tabular}{lll}
\hline BMI group $\left(\mathbf{K g} / \mathbf{m}^{\mathbf{2}}\right)$ & Number & Percentage \\
\hline $30-34.9$ (I) & 18 & 26.5 \\
$35-39.9$ (II) & 31 & 45.6 \\
$\geq 40$ (III) & 19 & 27.9 \\
Total & 68 & 100 \\
\hline
\end{tabular}

URICA SCORE: Based on the URICA score, the mean readiness to change score was $8.68 \pm 1.68$. Most of the study participants were contemplators $(73.5 \%)$. Details are in Table 3 .

Table 3. Urica score distribution table.

\begin{tabular}{lll}
\hline Readiness to change group & Number & Percentage \\
\hline$<8$ (Pre-contemplation) & 17 & 25 \\
$8-12$ (Contemplation) & 50 & 73.5 \\
$>12$ (Preparation) & 1 & 1.5 \\
Total & 68 & 100 \\
\hline
\end{tabular}

Multiple logistic regression did not reveal any significant relationship between readiness to change category and key socio-demographic variables as shown in Table 4.

Table 4. Multinomial logistic regression table of factors predicting readiness to change in study population.

\begin{tabular}{llll}
\hline Variables & Wald statistic & P Value & Adjusted Odds ratio (95\%CI) \\
\hline Occupation (Professional) & 0.76 & $0.38^{*}$ & $0.49(0.10-2.43)$ \\
Gender (Female) & 0.50 & $0.48^{*}$ & $1.71(0.39-7.53)$ \\
Marital status (married) & 0.78 & $0.38^{*}$ & $0.51(0.11-2.30)$ \\
\hline
\end{tabular}




\begin{tabular}{llll}
\hline Variables & Wald statistic & P Value & Adjusted Odds ratio (95\%CI) \\
\hline Ethnic group (Igbo) & 0.05 & $0.82^{*}$ & $1.22(0.23-6.57)$ \\
Age (<50 years) & 0.05 & $0.82^{*}$ & $0.85(0.20-3.60)$ \\
Education (tertiary) & 0.02 & $0.89^{*}$ & $1.14(0.18-7.38)$ \\
Income group (> $\mathrm{N40,000)}$ & 0.04 & $0.84^{*}$ & $1.14(0.31-4.17)$ \\
Self- perception of motivation (yes) & 0.001 & $0.98^{*}$ & $1.02(0.22-4.75)$ \\
Self-efficacy (No) & 0.28 & $0.60^{*}$ & $1.47(0.36-6.08)$ \\
Illness presentation (Nil) & 0.19 & $0.66^{*}$ & $1.36(0.34-5.39)$ \\
\hline
\end{tabular}

\section{Discussion}

Obesity is one of the greatest public health challenges of the 21 st century. Its prevalence has tripled in many countries worldwide since the $1980 \mathrm{~s}$, and continues to rise at an alarming rate, particularly in developing countries. ${ }^{2}$

The prevalence of obesity in this study was $17.43 \%$. This is comparable with other studies by Wahab et al in Katsina $(23 \%),{ }^{26}$ Puepet et al in Jos, Nigeria $(21.4 \%)^{27}$ and Adediran et al in Abuja (22.3\%). ${ }^{28}$ This was however higher than the prevalence found by Desalu et al in Ilorin $(9.8 \%),{ }^{29}$ and Iloh et al in Umuahia $(6.0 \%){ }^{30}$

Most of the study participants were in the 40-49 years age group. This shows that obesity is commoner in middle age agreeing with other studies done in Nigeria by Amole et al, ${ }^{31}$ Adediran et al, ${ }^{28}$ and Wahab et al. ${ }^{26}$ This is not surprising because people in this age group are more likely to be employed and have more disposable income. This may lead to consumption of excessive unsuitable food and when combined with sedentary life style, makes obesity inevitable. There were more females than males in the study $(76.5 \%$ vs. $23.5 \%$ ) i.e. ratio $3: 1$. Similar findings were noted in the WHO MONICA project where women had significantly higher prevalence rates of obesity than men. ${ }^{2}$ Other studies in Nigeria by Desalu et al, ${ }^{29}$ Adediran et al, ${ }^{28}$ and Wahab et al, ${ }^{26}$ also had similar findings. However a study done in Jos by Puepet showed that the female to male ratio was $1: 3{ }^{27}$

Most of the study participants had tertiary education (64\%). This was similar to a study done by Ojofeitimi et al who found out that in spite of the higher education of their subjects in a University community in South Western Nigeria, many of the respondents believed that being obese gave respect and that it was a sign of good living. ${ }^{32}$ This was however different from Adediran's study who found that participants with little or no formal education had the highest prevalence of obesity compared to those with formal education $(38.6 \%$ versus $16.9 \%){ }^{28}$

About $83.8 \%$ of the patients were married while only $10 \%$ were single. This is similar to findings reported by Wahab et al in Katsina, ${ }^{26}$ and Siminnialayi et al in Port-Harcourt. ${ }^{33}$ This result is reflective of the fact that those in their middle ages are more likely to be married. In contrast, Adediran et al also showed that a larger proportion of singles were obese than married $(25.0 \%$ versus $21.5 \%)$ but this difference was not statistically significant. ${ }^{28}$ This is probably because a large proportion of the sample population $(79.0 \%)$ were married. The effects of marriage and divorce on weight may be due to the influence of marriage on inducement to eat (e.g. shared meals) or on motivation for weight loss.
A large percentage of the patients were either professionals $(54.4 \%)$ or self-employed $(41.1 \%)$. This is also reflective of the age distribution of the patients with this age group likely to be working, and also more likely to have access to high energy foods. This group was also likely to be sedentary and not having time to exercise, as had been reported in other studies from other parts of Nigeria. ${ }^{34,35}$

Most of the participants were class II obese (45.6\%). A study done among male undergraduates at the University of Lagos revealed that most of the population studied fell within obese class I category. ${ }^{36}$ This study was also comparable to studies done by Iloh et al in Umuahia $(86.1 \%)^{30}$ and Adediran et al in Abuja (mean weight of 27.35 4.03 ). ${ }^{28}$ In contrast, the higher percentage of class II obesity in this study might be attributed to the fact that our study excluded the overweight and only focused on those whose BMI were more than $30 \mathrm{Kg} / \mathrm{m}^{2}$. The other studies included both overweight and obese patients.

All the study participants had very high abdominal circumference. The males had a mean abdominal circumference of $119.3 \pm 17.3 \mathrm{~cm}$ while that of the females was $111.2 \pm 8.9 \mathrm{~cm}$. These findings were much higher compared to studies done by Amole (male $=84.1 \pm 12.7$ and females $=90 \pm 14.6$ ) ${ }^{31}$ and Adediran et al (male $=83.75 \pm 11.34$ and female $=86.64 \pm 12.44) .{ }^{28}$ This might be because most of the study participants in the index study were in class II obesity. It is important to note that central obesity is not only a risk factor for cardiovascular disease worldwide but a cause of increased mortality in both men and women. ${ }^{2}$

The mean URICA score for the participants indicated that most were in contemplation. This is comparable to a study done by Larforge et al in the U.S.A. who found that $41 \%$ of their participants were in pre-contemplation, $18.5 \%$ were in contemplation, $24.5 \%$ in action and $41 \%$ in maintenance. ${ }^{37}$ Another study by Hawkins among African-American women showed that most of them were in pre-contemplation. ${ }^{38}$ These values are consistent with Prochaska's theory which states that most people who want to change their behaviour are either pre-contemplators or contemplators. ${ }^{23}$ This is in contrast to studies by Wee et al where most of their study participants were in advanced stages of weight loss. ${ }^{39}$ This might be because these two studies did not use the URICA scale to measure motivation. The stage of change is more useful than the URICA score in clinical practice because it can determine which intervention the clinician should provide. For example, during pre-contemplation and contemplation, patients are more likely to respond to a cognitive approach, such as discussing the benefits of habit change, possibly supported by written information. In the 
pre-contemplation stage, the patient perceives that the disadvantages of changing outweigh the benefits, whereas this pattern is reversed in the action stage.

The study did not find any statistically significant relationships between socio-demographic variables and stage of readiness to change. Ghannadiasl et al found that Iranian women with higher waist hip ratio were more likely to have higher readiness to change scores and tended to be in higher action categories. ${ }^{40}$

It was also interesting that self-perception of motivation to change and self-assessment of efficacy were not significantly related to actual stage of change as measured by the URICA score. This would imply that primary care physicians should be careful since patients' self-perception and self-assessment of readiness to change might not correlate with an objective assessment of readiness to change.

LIMITATION: The study population was not diverse, since only literate obese patients were studied. These results should not be generalised to a population with a significant proportion of non-literate members. The URICA score was also not independently validated for a Nigerian population.

\section{Conclusion}

This study has shown that the prevalence of obesity among literate patients attending the General Outpatient department of Bingham University Teaching Hospital Jos is $17.43 \%$. Most $(73.5 \%)$ of the literate obese patients were found to be in the contemplation stage. This has implications for physicians offering lifestyle behaviour change interventions in primary care.

\section{Acknowledgements}

The authors wish to declare that they have no financial or personal relationship(s) which may have inappropriately influenced them in writing this paper.

The authors appreciate the support of the Management, OPD staff and patients of Bingham University Teaching Hospital Jos.

\section{References}

[1] Hamdy O, Uwaifo GI, Oral EA. Obesity. Medscape reference. [Accessed 20/03/15]. Available from http://emedicine.medscape.com/article/123702.

[2] World Health Organization. Obesity and overweight fact sheet. [Accessed 10pm 6/10/11]. Available from http://www.who.int/mediacentre/factsheets/fs311/en/.

[3] Tan KCB. Appropriate body-mass index for Asian populations and its implications for policy and intervention strategies. Lancet. 2004;363(9403):157-63.

[4] Kelly T, Yang W, Chen CS, Reynolds K, He J. Global burden of obesity in 2005 and projections to 2030 . Int. J Obes (Lond) 2008;32(9):1431-7.

[5] Carroll JF, Chiapa AL, Rodriquez M, Phelps DR, Cardarelli
KM, Vishwanatha JK et al. Visceral fat, waist circumference, and BMI: Impact of race/ethnicity. Obesity. 2008;16(3):600-7.

[6] Prentice AM \&Jebb SA. Beyond body mass index. Obes Rev. 2001;2:141-7.

[7] Flegal KM, Carroll MD, Ogden CL and Curtin LR. Prevalence and trends in obesity among US adults, 1999-2008. JAMA 2010;303(3):235-41.

[8] Finucane MM, Stevens GA, Cowan MJ, Danaei G, Lin JK, Paciorek CJ, et al. National, regional, and global trends in body-mass index since 1980: systematic analysis of health examination surveys and epidemiological studies with 960 country-years and 9.1 million participants. Lancet. 2011;377(9765):557-67.

[9] Amoah AGB. Sociodemographic variations in obesity among Ghanaian adults. Public Health Nutr 2003,6:751-7

[10] Sodjinou R, Agueh V, Fayomi B, Delisle H. Obesity and cardio-metabolic risk factors in urban adults of Benin: relationship with socio-economic status, urbanisation, and lifestyle patterns. BMC Public Health. 2008;8:84.

[11] Tanumidardjo SA, Anderson C, Kaufer-Horwitz M. Poverty, obesity, and malnutrition: An international perspective recognizing the paradox. J Am Diet Assoc. 2007;107:1966-72.

[12] Abubakari AR, Lauder W, Agyemang C, Jones M, Kirk A, Bhopal RS. Prevalence and time trends in obesity among adult West African populations: a meta-analysis. Obes Rev 2008;9(4):297-311.

[13] Russel SH. Realistic approach to counselling in the office setting. Am FamPhy. 2009;79(4):277-84.

[14] Jonas S. Mobilizing Motivation. In: Jonas S and Phillips EM (eds). ACSM's Exercise is Medicine: A Clinician's Guide to Exercise Prescription. Lippincott Williams and Wilkins: Philadelphia, USA. 2009;61-69.

[15] Rubak S, Sandbæk A, Lauritzen T, Christensen BO. Motivational interviewing: a systematic review and metaanalysis .Br J Gen Pract. 2005;55(513):305-12.

[16] Diclemente CC, Bellino LE, Neavins TM. Motivation for change in alcoholism. Alcohol res health. 1999;23(2):86-92.

[17] Wadden TA, Berkowitz RI, Womble LG, Sarwer DB, Phelan S, Cato RK et al. Randomized trial of lifestyle modification and pharmacotherapy for obesity. N Engl J Med 2005;353:211120 .

[18] Miller WR, Rollnick S. Ten things that motivational interviewing is not. BehavCognPsychother 2009;37:129-40.

[19] Edell BH, Edington S, Herd B, O’Brien RM, Witkin G. Selfefficacy and self-motivation as predictors of weight loss. Addict Behav 1987;12:63-66.

[20] Williams GC, Grow VM, Freedman ZR, Ryan RM, Deci EL. Motivational predictors of weight loss and weight-loss maintenance. J PersSocPsychol 1996;70:115-126.

[21] Rollnick S, Miller WR, Butler CC. Motivational interviewing in health care: Helping patients change behaviour. New York: Guilford Press, 2008.

[22] McConnaughy. EI, Prochaska, JO, Velicer WF. Stages of change in psychotherapy: Measurement and sample profiles. Psychotherapy: Theory. Research, and Practice. 1983;20:368-75. 
[23] Prochaska JO, DiClementi CC, Necross JC. In search of how people change. Applications to addictive behaviours. Am Psychol 1992;47:1102-14.

[24] West RJ. Time for a change: Putting the transtheoretical (stages of change) model to rest. Addiction. 2005;100:1036-9

[25] Field CA, Adinoff B, Harris TR, Ball SA, Carroll KM. Construct, concurrent and predictive validity of the URICA: Data from two multisite clinical sites. Drug Alcohol Depend. 2009;101(1-2):115-23.

[26] Wahab KW, Mohmoud US, Bashir OY, Maruf G, Gbadamosi A, Mohmoud IY. Prevalence and determinants of obesity. A cross sectional study of an adult northern Nigerian population. Int Arch Med. 2011;4:10(1):1186/1755-82.

[27] Peupet FH, Zoaka AI, Chuhwak EK. Prevalence of overweight and obesity among urban Nigerian Adults in Jos. Highland Med Res J. 2002;1(1):13-6.

[28] Adediran OS, Okpara IC, Adeniyi OS, Jimoh AK. Obesity prevalence and its associated factors in an urban and rural area of Abuja Nigeria. Glob Adv Res J Med Med Sci. 2012;1(8):237-41.

[29] Desalu OO, Salami AK, Oluboyo PO, Olumoye JK. The prevalence and socio-demographic determinants of obesity among adults in an urban Nigerian population. Sahel medical journal 2008;11(2):61-4.

[30] Iloh G, Amadi A, Nwankwo B, Ugwu VC. Obesity in adult Nigerians: A study of its prevalence and common primary comorbidities in a semi-urban mission general hospital in SouthEastern Nigeria. Niger J Med. 2010;19(4):22-9.

[31] Amole IO, OlaOlorun AD, Odeigah LO, Adesina SA. The prevalence of abdominal obesity and hypertension amongst adults in Ogbomoso, Nigeria. Afr J Prim Health Care Fam Med. 2011;2(1):20-7.
[32] Ojofeitimi EO, Adeyeye AO, Fadiora AO, Kuteyi AO, Faborode TG, Adegbenro CA et al. Awareness of obesity and its health hazard among women in a university community. Pakistan Journal of Nutrition 2007;6(5):502-5.

[33] Siminnialayi IM, Emem-Chioma PC, Dapper DV. The prevalence of obesity as indicated by BMI and waist circumference among Nigerian adults attending family medicine clinics as outpatients in Rivers State. Niger J Med. 2008;17(3):430-5.

[34] Fadupin GT, Joseph EU, Keshinro OO. Prevalence of obesity among Type 2 Diabetic patients in Nigeria. A case study of patients in Ibadan, Oyo state Nigeria. Afr J Med Sci. 2004;33(4):381-4.

[35] Amodu PH, Mba IO, Lawson L. Prevalence of Obesity and dyslipidemia in hypertensives in Abuja Nigeria. Scan J Clin Lab Inv. 2005;20(24):14-7.

[36] Adeogun OJ, Ligali LA. The prevalence of overweight and obesity in an institutionalized multi ethnic based male adult sample. Int J HumanitSoc Sci. 2013;3(5);34-9.

[37] Laforge RG, Velicer WF, Richmond RL, Owen N. Stage distributions for five health behaviours in the USA and Australia. Prev Med. 1999;28:61-74.

[38] Hawkins DS, Hornsby PP, Scorling JB. Stages of change and weight loss among rural African American women. Obes Res. 2001;9:59-67.

[39] Wee CC, Davis RB, Phillips RS. Stage of readiness to control weight and adopt weight control behaviours in primary care. $\mathrm{J}$ Gen Intern Med. 2005; 20:410-415.

[40] Ghannadiasl F, Mahdavi R, AsghariJafarabadi M. Assessing Readiness to Lose Weight among Obese Women Attending the Nutrition Clinic. Health PromotPerspect. 2014;4(1):27-34. 